Available online at https://jurnal.stmikroyal.ac.id/index.php/jurdimas

\title{
SOSIALISASI FILM ANIMASI 2D VECTOR DAMPAK BENCANA ALAM DI INDONESIA DENGAN NILAI-NILAI ISLAMI
}

\author{
Tri Yuliati*1, Erna Alimudin ${ }^{1}$ \\ ${ }^{1}$ Teknik Informatika, Sekolah Tinggi Teknologi Dumai \\ Email: *triyuliati00@gmail.com
}

\begin{abstract}
The Community Service Program (PPM) which is carried out aims to implement multimedia as a learning media. The learning media created are 2D Vector animated films with background stories on natural disasters in Indonesia (tsunami, mount merapi, and landslides) with Islamic values in them. The screening of this animated film makes it easier for children to understand the catastrophe in the form of natural disasters such as what and what attitude needs to be taken as a Muslim. Children are also motivated to always remember the prayers that have been invited in TPQ. They can pray these prayers when hit by disaster, this animated film is made with the aim that children are easier to instill religious attitudes that need to be taken when experiencing disaster. So, children do not drag on sadness, not prolonged trauma, and can rise again to organize the future. This animated film can also be used by teachers and parents to provide lessons to build children's religious attitudes so that ank is able to cope with calamities if one day faces disaster. Participants of the socialization consisted of children which aged around 5 to 12 years or called the "cabe rawit" class with the number of students around 12 children and 2 teachers for each class. The socialization activity was held at the TPQ Nurul Huda Dumai. The purpose of the socialization is the student can understand the element of Islamic value learning education embedded in the $2 \mathrm{D}$ vector animated film shown.
\end{abstract}

Keywords: animation 2D vector, film, motion graphic

\begin{abstract}
Abstrak: Program Pengabdian pada Masyarakat (PPM) yang dilaksanakan bertujuan untuk menerapkan multimedia sebagai media pembelajaran. Media pembelajaran yang dibuat adalah film animasi 2D Vector dengan latar cerita bencana alam di Indonesia (tsunami, gunung merapi, dan longsor) dengan nilai-nilai islami didalamnya. Pemutaran film animasi ini membuat anakanak menjadi lebih mudah untuk memahami musibah dalam bentuk bencana alam seperti apa dan sikap bagaimana yang perlu diambil sebagai seorang muslim. Anak-anak pun termotivasi senantiasa mengingat doa yangs udah diajakran di TPQ. Doa-doa tersebut dapat mereka panjatkan ketika terkena musibah, Film animasi ini dibuat dengan tujuan agar anak-anak lebih mudah untuk ditanamkan sikap religius yang perlu diambil ketika mengalami musibah. Sehingga, anakanak tidak berlarut-larut dalam kesedihan, tidak trauma berkepanjangan, dan dapat bangkit kembali untuk menata masa depan. Film animasi ini juga dapat digunakan oleh guru maupun orang tua untuk memberikan pelajaran untuk membangun sikap religius anak agar anak mampu mengatasi musibah. Peserta sosialisasi terdiri dari anak-anak usia 5 sampai 12 tahun atau dinamakan kelas cabe rawit dengan jumlah siswa sekitar 12 orang perkelasnya serta 2 guru untuk tiap kelas. Kegiatan sosialisasi diadakan di TPQ Nurul Huda Dumai. Setelah kegiatan diharapkan anak-anak dapat melihat unsur edukasi pembelajaran nilai islami yang ditanamkan pada media film animasi 2D vector yang diperlihatkan.
\end{abstract}

Kata kunci: animasi 2D vector, film, motion graphic 
Available online at https://jurnal.stmikroyal.ac.id/index.php/jurdimas

\section{PENDAHULUAN}

Bencana alam merupakan bencana yang diakibatkan oleh peristiwa atau serangkaian peristiwa yang disebabkan oleh alam antara lain berupa gempa bumi, tsunami, gunung meletus, banjir, kekeringan, angin topan, dan tanah longsor. (Presiden Republik Indonesia, 2007) Badan Nasional Penanggulangan Bencana mengumpulkan tren kejadian bencana alam dalam 10 tahun terakhir di Indonesia seperti yang dirujuk pada gambar 1.

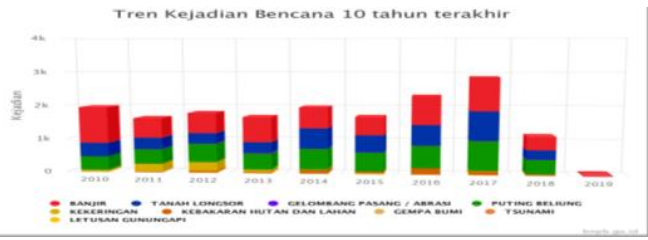

Gambar 1. (Badan Nasional Penanggulangan Bencana, 2019)

Gambar 1 menunjukkan bahwa dalam 10 tahun terakhir Indonesia masih kerap mengalami bencana alam. Perlu diketahui juga, bahwa Indonesia masih rawan bencana dalam beberapa tahun ke depan. (Seluma, Guntar, \& Sugandi, 2018)

Bencana alam mengakibatkan timbulnya korban jiwa manusia, kerusakan lingkungan, kerugian harta benda. Korban bencana alam tidak hanya orang dewasa tapi juga anak-anak. Oleh karena itu, dampak psikologis yang dialami korban bencana alam perlu menjadi perhatian yang serius.

Dampak psikologis pada anak-anak korban bencana yang dimaksud antara lain : (1) Kesedihan mendalam karena kehilangan kasih sayang keluarga bagi anak yang ditinggalkan. Hal ini membuat hilangnya semangat hidup. (2) Hilangnya harga diri dan kemampuan seorang anak karena di tempat pengungsian mereka menerima belas kasihan dari pihak lain dan bahkan seringkali menjadi tontonan. (Adi, Amawidyati, \& Utami, n.d.)

Dampak psikologis ini mengakibatkan timbulnya rasa jenuh karena tidak dapat memastikan sampai kapan harus mengungsi, mendatangkan perasaan tidak berdaya, ketakutan dan bahkan perasaan putus asa menghadapi kemungkinan bencana yang tidak mungkin dihindari, (tidak dapat melawan kehendak Tuhan). Akibatnya timbul perasaan marah, stres atau frustrasi dengan situasi dan kondisi yang serba tidak menentu, trauma, putus asa, merasa tidak berdaya dan ketidakpastian terhadap masa depannya. (Rusmiyati \& Hikmawati, n.d.)

Sikap positif seperti ketabahan, adanya penerimaan, serta hubungan yang positif dengan orang lain yang ditunjukkan oleh korban gempa tersebut mengarah kepada terbentuknya kondisi psikologis yang positif (positive psychological functioning), yang membawa kepada terwujudnya kesejahteraan psikologis (psychological well-being) dalam diri seseorang. Kesehatan mental seseorang ketika mengalami musibah sangat dipengaruhi oleh religiutas yang tertanam padanya. Sikap religius dapat meningkatkan psycholoical well-being pada diri seseorang. Seseorang yang memiliki kepercayaan terhadap agama yang kuat akan menumbuhkan kepuasan dan kebahagiaan personal. (Argyle, 2001)

Hal ini membuat dampak negatif dari peristiwa traumatis yang dialami akan menjadi lebih mudah diatasi dibandingkan seseorang yang tidak memiliki kepercayaan terhadap agama yang kuat. Sikap religiusitas inilah yang menjadi modal utama untuk seseorang yang harus mengatasi trauma atas bencana yang dialami. Oleh karena itu, setelah mengalami bencana, kehidupan seseorang yang religius dapat dengan mudah mengatasi kesedihan, kegelisahan, serta kekecewaan yang dirasakannya.

Religiusitas dalam menghadapi bencana perlu dibangun sejak usia dini. Anak usia dini pada rentang usia 3-5 tahun dapat ditanamkan nilai-nilai tersebut melalui PAUD (Pendidikan Anak Usia Dini). (Hastuti, 2015)

Beberapa metode dapat digunakan untuk mengenalkan sikap religiusitas yang perlu diambil. Salah satunya melalui media pembelajran berbasis multimedia. Multimedia berasal dari kata multi dan media. Multi berarti banyak dan media berarti perantara. Multimedia dapat diartikan sebagai kombinasi dari teks, gambar atau foto, animasi, video, 
Available online at https://jurnal.stmikroyal.ac.id/index.php/jurdimas

maupun suara yang disampaikan melalui computer atau peralatan manipulasi elektronik dan digitalnya. Selain itu, istilah multimedia juga dapat diartikan sebagai kumpulan teknologi yang beragam yang mengkombinasikan media visual (penglihatan) dan audio (pendengaran) dengan cara-cara yang baru atau modern untuk tujuan komunikasi. (Ulfa, 2013) Media pembelajaran berbasis multimedia yang dibuat adalah film animasi.

\section{METODE}

Animasi yang digunakan sebenarnya adalah rangkaian gambar yang disusun berurutan atau dikenal dengan istilah frame. Satu frame terdiri dari satu gambar jika susunan gambar tersebut ditampilkan bergantian dengan waktu tertentu maka akan terlihat bergerak. Satuan yang dipakai adalah frame per second (fps). Misalkan animasi diset $25 \mathrm{fps}$ berarti animasi tersebut terdiri dari 25 gambar dalam satu detik. Semakin besar nilai fps, maka akan dapat terbentuk animasi yang terkesan halus (Sukarno, 2014).

Animasi yang dibuat adalah 2D vector dengan motion graphic. Hal ini menjadikan tampilan animasi bagaikan potonganpotongan media visual berbasis waktu yang menggabungkan film dan desain grafis. Animasi ini dibentuk dari gabungan animasi 2D, tipografi, ilustrasi, dan musik latar belakang. Alat bantu pembuatan film animasi antara lain Adobe Premiere CS6 dan Adobe After Effect CS6.

Tujuan dari kegiatan ini adalah untuk memberikan sosialisasi mengenai dampak bencana alam melalui video animasi vector yang dibuat menggunakan adobe after effect. Kegiatan ini menggunakan metode demonstrasi yang dilakukan dengan menjelaskan apa itu bencana alam kepada anak-anak di TPQ sambil memutar video film animasi bencana alam dan berinteraksi dengan anakanak beserta guru ngaji sambil sesekali menanyakan do'a dan hapalan yang sudah anak-anak pelajari dari guru ngajinya.
Melalui metode ini ada beberapa bermanfaat yang dirasakan anak-anak TPQ :

1. Anak-anak bisa memahami dampak bencana alam dari video film animasi melalui sebuah tanya jawab dan diskusi

2. Anak-anak bisa mengingat hapalan doadoa yang telah mereka pelajari dan menerapkannya kedalam kehidupan sehari-hari melalui dari pemutaran video film animasi tersebut.

3. Anak-anak bisa tahu bagaimana cara menjaga alam dengan contoh kecil tidak membuang sampah sembarangan dan turut memlihara tanaman yang ada disekitar rumah mereka.

\section{PEMBAHASAN}

Film animasi yang di pertontonkan kepada anak-anak mampu menjadi media pembelajaran menarik untuk anak sehingga anak tidak merasa bosan dan membuat belajar menjadi menyenangkan karena adanya unsur hiburan. Melalui media film animasi ini disampaikan nilai-nilai dan norma-norma religious saat musibah terjadi maupun kehidupan sehari-hari.

Salah satu bencana yaitu tsunami diilustrasikan dalam bentuk scene saat sekelompok masyarakat berusaha untuk lari dari ombak tinggi yang dirujuk pada gambar 2.

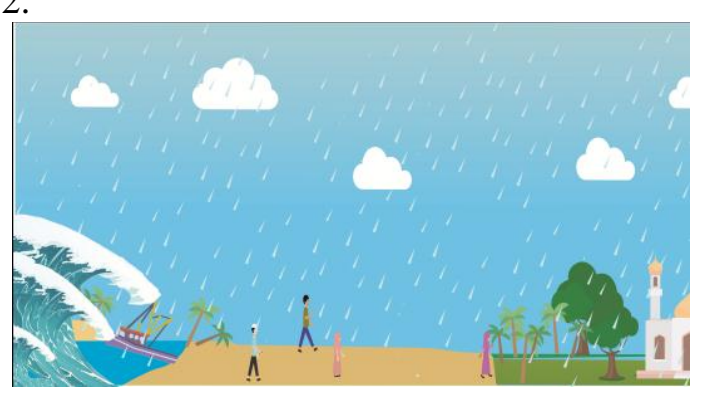

Gambar 2. Scene Tsunami

Kegiatan sosialisasi ini berlangsung selama 2 jam di TPQ Nurul Huda Dumai. Selama kegiatan berlangsung didokumentasikan dalam foto-foto sebagai berikut : 
Available online at https://jurnal.stmikroyal.ac.id/index.php/jurdimas

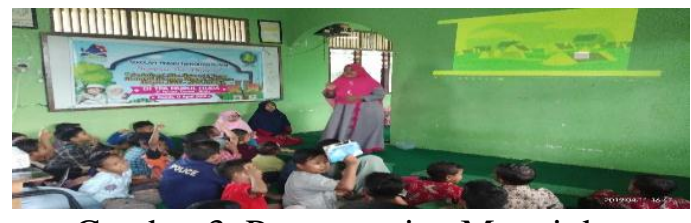

Gambar 3. Penyampaian Materi dan Pemutaran Film

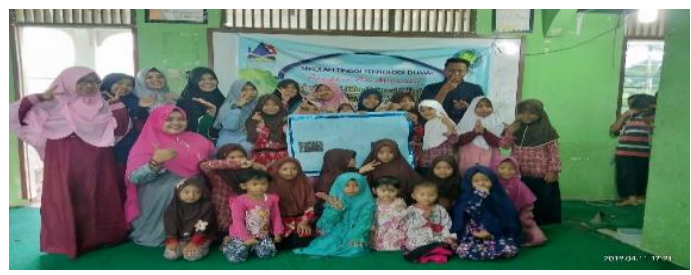

Gambar 4. Sesi foto bersama bersama anakanak TPQ dan Guru

Cerita dari film animasi ini megenai pembelajaran pada saat adanya musibah. Sikap yang perlu diambil anak-anak adalah senantiasa mengingat Allah SWT. Anakanak kemudian beramai-ramai mempraktekkan doa yang telah mereka dapatkan di TPQ. Selain itu, juga sebagai pengingat manusia akan Tuhannya, serta pengingat agar selalu tetap bertawakkal, berdoa dan berserah diri kepada penciptanya.

\section{SIMPULAN}

Bencana alam bisa terjadi kapan saja dan anak-anak bisa saja menjadi korban. Anak-anak perlu diatasi masalah traumatisnya dengan menanamkan sikap religius. Sikap religius perlu diajarkan sejak dini. Sikap religius dapat diajarkan melalui media pembelajaran dalam bentuk film animasi 2D vector yang menarik seperti yang telah dibuat dalam pengabdian masyarakat ini.

\section{UCAPAN TERIMA KASIH}

Penulis mengucapkan terima kasih yang sebesar-besarnya kepada Ketua STT Dumai, LPPM STT Dumai dan keluarga besar STT Dumai atas kontribusinya baik dari segi materil dan immateril dalam pelaksanaan kegiatan pengabdian kepada masyarakat ini bisa terlaksana dengan baik.

\section{DAFTAR PUSTAKA}

Adi, S., Amawidyati, G., \& Utami, M. S. (n.d.). Religiusitas dan Psychological Well - Being Pada Korban Gempa, 34(2), 164-176.

Argyle, M. (2001). The Psychology of Happiness. 2nd Edition. Sussex Routledge.

Badan Nasional Penanggulangan Bencana. (2019). Tren Kejadian Bencana 10 tahun terakhir. Retrieved from https://bnpb.go.id//definisi-bencana

Hastuti, D. (2015). PENANAMAN NILAINILAI AGAMA PADA ANAK USIA DINI DI RA TAHFIDZ AL-QUR'AN JAMILURRAHMAN BANGUNTAPAN BANTUL.

Presiden Republik Indonesia. UndangUndang Republik Indonesia tentang Penanggulangan Bencana (2007). Indonesia.

Rusmiyati, C., \& Hikmawati, E. (n.d.). PENANGANAN DAMPAK SOSIAL PSIKOLOGIS KORBAN BENCANA MERAPI (Sosial Impact of Psychological Treatment Merapi Disaster Victims), 17(02), 97-110.

Seluma, K., Guntar, D., \& Sugandi, W. (2018). Sosialisasi Potensi Bencana dan Sistem Informasi Geografi ( SIG ), 2(1), 59-68.

Sukarno, I. (2014). Perancangan motion graphic ilustratif mengenai majapahit untuk pemudapemudi. Jurnal Tingkat Sarjana Bidang Senirupa Dan Desain.

Ulfa, A. (2013). Perancangan media promosi program studi desain komunikasi visual universitas negeri padang berbasis animasi'. Seni Rupa, Fakultas Bahasa Dan Seni, Universitas Negeri Padang, Padang. 